\title{
THE EFFECTS OF RAPID MASSIVE HAEMORRHAGE AND RETRANSFUSION ON VARIOUS CARDIOVASCULAR PARAMETERS IN THE DOG
}

\author{
David Evans, M.D., F.R.C.P.(c), and H. W. Boyes, M.D.
}

THE EFFECTS OF HAEMORRHAGE have been investigated extensively, but this usually involves various degrees of trauma to the animal above and beyond that of the actual experiment. We have tried to avoid this as much as possible by a technique of chronic catheterization of various blood vessels some months prior to the actual experiment. At the time of the investigation, therefore, the only surgical insult is that of the massive haemorrhage.

\section{METHOD}

Healthy mongrel dogs weighing 20 to $25 \mathrm{~kg}$ are used for each experiment. Two months prior to each study each dog is prepared by the insertion of chronically implanted catheters into the left atrium, superior vena cava, and pulmonary artery as described previously. ${ }^{1}$ One week later splenectomy is performed through a mid-line upper abdominal incision. As stated above, an interval of two months is allowed before the animal is studied, during which time complete recovery and healing of wounds is ensured.

On the day of the study the dog is induced with a sleep dose of thiopentone, and anaesthesia is maintained with a mixture of oxygen and nitrous oxide in equal proportions. The animal is rendered immobile by the use of a continuous infusion of 5 per cent dextrose in water containing $500 \mathrm{mg}$ of succinylcholine. The distal ends of the catheters are exposed by small incisions and a \#16 Medicut catheter is inserted percutaneously into the left femoral artery. The four catheters are connected to Statham Pressure Transducers and a Sanborn Multichannel Recorder. The catheter in the left femoral artery is also connected to a Gilford Cuvette Densitometer and a Harvard Continuous Automatic Withdrawal Pump through a three-way stopcock and plastic tubing. The right femoral artery is exposed and a wide bore catheter is inserted for bleeding. The distal end is inserted into a $500 \mathrm{cc}$ vacuum bottle containing $50 \mathrm{mg}$ heparin.

Sixty minutes after the induction of anaesthesia, when the cardiovascular status is stable, the dog is heparinized (dose $2 \mathrm{mg} / \mathrm{kg}$ ) and baseline pressures are recorded from the left atrium, superior vena cava, left femoral artery, and pulmonary artery. A baseline cardiac output is also measured by the dye dilution technique, injections of $5.0 \mathrm{mg}$ of indocyanine green being made into the left atrium. The output from the densitometer is recorded on a Texas Rectiriter and also integrated through a Lexington Cardiac Output Computer. Bleeding is then

-Department of Anaesthesia, University of Toronto and Toronto Western Hospital, Toronto, Ontario. Please address reprint requests to: Dr. David Evans, Toronto Western Hospital, 399 Bathurst Street, Toronto. 
started at a rate of $100-150 \mathrm{cc} / \mathrm{min}$ until a mean femoral artery pressure of $30 \mathrm{~mm}$ $\mathrm{Hg}$ is reached. Pressures are recorded continuously during this period. Cardiac output is measured once during the bleeding period and also when it is completed. The shed blood is now returned to the animal through a forearm vein at a rate similar to that of bleeding. Again, pressures are recorded and cardiac output measured, once during the transfusion, once immediately on completion, and again fifteen minutes later. The wounds are then closed, the animal is allowed to recover, and the studies are repeated on the same animal at a later date under similar conditions.

\section{Results}

A total of three dogs were investigated (see Tables I-V), two of them being studied on two different occasions (experiments $1,1_{\mathrm{A}}, 2,2 \mathrm{~A}$ ).

\section{Mean pulmonary artery pressure (Fig. 1)}

The average baseline mean pressure was $13 \mathrm{~mm} \mathrm{Hg}$, with a range of 12 to 15 $\mathrm{mm} \mathrm{Hg}$. There was good correlation between the amount of blood loss and the fall in mean pressure. Retransfusion of blood caused an increase in pressure above the baseline figures. The overshoot reached an average of $18 \mathrm{~mm} \mathrm{Hg}$-an increase of about 25 per cent. Fifteen minutes after transfusion the pressure had returned to baseline levels.

TABLE I

DoG 1

\begin{tabular}{|c|c|c|c|c|c|c|c|c|}
\hline Time & $\begin{array}{c}\text { FAP } \\
(\mathrm{mm} \mathrm{Hg})\end{array}$ & $\begin{array}{c}\text { PAP } \\
(\mathrm{mm} \mathrm{Hg})\end{array}$ & $\begin{array}{c}\text { MFAP } \\
(\mathrm{mm} \mathrm{Hg})\end{array}$ & $\begin{array}{c}\text { MPAP } \\
(\mathrm{mm} \mathrm{Hg})\end{array}$ & $\begin{array}{c}\text { MSVC } \\
(\mathrm{mm} \mathrm{Hg})\end{array}$ & $\begin{array}{c}\text { MLLAP } \\
(\mathrm{mm} \mathrm{Hg})\end{array}$ & $\begin{array}{l}\text { Cardiac } \\
\text { output } \\
\text { (L/min) }\end{array}$ & $\begin{array}{l}\text { Blood } \\
\text { loss/trans } \\
\text { (cc) }\end{array}$ \\
\hline $0+60$ & 175 & $\underline{15}$ & & & & & & \\
\hline \multirow[t]{2}{*}{$\min$} & $\overline{120}$ & $\overline{10}$ & 150 & 12 & +2 & +2 & 4.2 & - \\
\hline & 180 & $\underline{14}$ & & & & & & \\
\hline \multirow[t]{2}{*}{$15 \mathrm{sec}$} & $\overline{120}$ & $\overline{8}$ & 150 & 10 & +2 & +2 & 4.0 & 100 \\
\hline & 175 & $\underline{10}$ & & & & & & \\
\hline \multirow[t]{2}{*}{$2 \mathrm{~min}$} & $\overline{120}$ & $\overline{6}$ & 140 & 7 & +2 & +2 & 3.2 & 250 \\
\hline & 130 & S & & & & & & \\
\hline $3 \frac{1}{2} \mathrm{~min}$ & $\overline{70}$ & $\overline{3}$ & 110 & 5 & 0 & 0 & - & 400 \\
\hline $4 \frac{1}{2} \min$ & - & $\overline{6}$ & 30 & 3 & -2 & -2 & - & 550 \\
\hline \multirow[t]{2}{*}{$15 \mathrm{sec}$} & - & $\overline{2}$ & 40 & 3 & -2 & -1 & - & 100 \\
\hline & & 10 & & & & & & \\
\hline \multirow[t]{2}{*}{$1 \frac{1}{2} \mathrm{~min}$} & - & $\overline{8}$ & 50 & 9 & -1 & +2 & - & 200 \\
\hline & 75 & 18 & & & & & & \\
\hline \multirow[t]{2}{*}{$3 \mathrm{~min}$} & $\overline{40}$ & $\overline{8}$ & 60 & 14 & +1 & +5 & 2.2 & 400 \\
\hline & $\frac{80}{40}$ & $\frac{22}{12}$ & & & & & & \\
\hline \multirow[t]{2}{*}{$4 \frac{1}{2} \min$} & 40 & 12 & 60 & 17 & +4 & +8 & 3.0 & 500 \\
\hline & 160 & 17 & & & & & & \\
\hline $10 \mathrm{~min}$ & $\overline{110}$ & $\overline{8}$ & 135 & 10 & +2 & +4 & 3.8 & - \\
\hline
\end{tabular}


TABLE II

Dog la

\begin{tabular}{|c|c|c|c|c|c|c|c|c|}
\hline Time & $\begin{array}{c}\text { FAP } \\
(\mathrm{mm} \mathrm{Hg})\end{array}$ & $\begin{array}{c}\text { PAP } \\
(\mathrm{mm} \mathrm{Hg})\end{array}$ & $\begin{array}{c}\text { MFAP } \\
(\mathrm{mm} \mathrm{Hg})\end{array}$ & $\begin{array}{c}\text { MPAP } \\
(\mathrm{mm} \mathrm{Hg})\end{array}$ & $\begin{array}{c}\text { MSvC } \\
\text { (mm Hg) }\end{array}$ & $\begin{array}{c}\mathrm{MLAP} \\
(\mathrm{mm} \mathrm{Hg})\end{array}$ & $\begin{array}{c}\text { Cardiac } \\
\text { output } \\
\text { (L/mm) }\end{array}$ & $\begin{array}{l}\text { Blood } \\
\text { loss/trans } \\
\text { (cc) }\end{array}$ \\
\hline $0+60$ & 200 & 16 & & & & & & \\
\hline $\min$ & $\begin{array}{l}\overline{135} \\
180\end{array}$ & $\overline{8}$ & 170 & 12 & -2 & +3 & 4.8 & - \\
\hline $15 \mathrm{sec}$ & $\begin{array}{l}110 \\
160\end{array}$ & $\overline{10}$ & 150 & - & -2 & +3 & 4.0 & 200 \\
\hline $1 \frac{1}{2} \mathrm{~min}$ & $\begin{array}{l}\overline{110} \\
120\end{array}$ & $\overline{8}$ & 145 & 9 & -2 & +1 & 2.2 & 250 \\
\hline $4 \mathrm{~min}$ & $\overline{60}$ & - & 80 & 2 & -3 & -2 & - & 500 \\
\hline $5 \mathrm{~min}$ & - & - & 28 & 0 & -3 & -2 & - & 600 \\
\hline $15 \mathrm{sec}$ & - & $\frac{-}{8}$ & 35 & 2 & -3 & 0 & - & - \\
\hline $2 \min$ & $\overline{80}$ & $\begin{array}{r}\overline{4} \\
16\end{array}$ & 35 & 6 & -2 & +2 & - & - \\
\hline $4 \mathrm{~min}$ & $\begin{array}{l}40 \\
90 \\
\end{array}$ & $\begin{array}{r}8 \\
26 \\
\end{array}$ & 55 & 12 & 0 & +6 & 1.8 & - \\
\hline $5 \mathrm{~min}$ & $\begin{array}{r}50 \\
180 \\
\end{array}$ & $\begin{array}{l}12 \\
18 \\
\end{array}$ & 75 & 18 & -2 & +8 & 2.8 & - \\
\hline $15 \mathrm{~min}$ & $\overline{120}$ & $\overline{10}$ & 150 & 12 & 0 & +5 & 3.5 & - \\
\hline
\end{tabular}

TABLE III

Dog 2

\begin{tabular}{|c|c|c|c|c|c|c|c|c|}
\hline Time & $\begin{array}{c}\text { FAP } \\
(\mathrm{mm} \mathrm{Hg})\end{array}$ & $\begin{array}{c}\text { PAP } \\
(\mathrm{mm} \mathrm{Hg})\end{array}$ & $\begin{array}{c}\text { MPAP } \\
(\mathrm{mm} \mathrm{Hg})\end{array}$ & $\begin{array}{c}\text { MPAP } \\
(\mathrm{mm} \mathrm{Hg})\end{array}$ & $\begin{array}{c}\text { MSvC } \\
(\mathrm{mm} \mathrm{Hg})\end{array}$ & $\begin{array}{c}\text { MLAP } \\
(\mathrm{mm} \mathrm{Hg})\end{array}$ & $\begin{array}{c}\text { Cardiac } \\
\text { output } \\
\text { (L/min) }\end{array}$ & $\begin{array}{l}\text { Blood } \\
\text { loss/trans. } \\
\text { (cc) }\end{array}$ \\
\hline $0+60$ & 160 & $\underline{17}$ & & & & & & \\
\hline \multirow[t]{2}{*}{$\min$} & $\overline{110}$ & $\overline{12}$ & 135 & 15 & +4 & +2 & 4.0 & - \\
\hline & $\underline{165}$ & 16 & & & & & & \\
\hline \multirow[t]{2}{*}{$20 \mathrm{sec}$} & $\overline{110}$ & $\overrightarrow{10}$ & 140 & 14 & +4 & +2 & 4.2 & 100 \\
\hline & 80 & 10 & & & & & & \\
\hline $3 \mathrm{~min}$ & $\overline{60}$ & $\overline{4}$ & 70 & 7 & 0 & 0 & 1.9 & 400 \\
\hline \multirow{2}{*}{5 min } & - & - & 32 & 2 & -2 & -2 & - & 600 \\
\hline & 65 & & & & & & & \\
\hline \multirow[t]{2}{*}{$30 \mathrm{sec}$} & $\overline{35}$ & - & 45 & 3 & -1 & -1 & - & 100 \\
\hline & 70 & 8 & & & & & & \\
\hline \multirow{2}{*}{$2 \mathrm{~min}$} & $\overline{35}$ & $\overline{4}$ & 50 & 6 & - & +2 & 一 & - \\
\hline & 80 & 18 & & & & & & \\
\hline \multirow[t]{2}{*}{$3 \frac{1}{2} \mathrm{~min}$} & $\overline{40}$ & $\overline{8}$ & 50 & 12 & +1 & +5 & $1 . S$ & 400 \\
\hline & 90 & $\underline{26}$ & & & & & & \\
\hline \multirow[t]{2}{*}{$5 \mathrm{~min}$} & $\overline{50}$ & $\overline{16}$ & 55 & 21 & +2 & +8 & 1.8 & 500 \\
\hline & $\underline{160}$ & $\underline{20}$ & & & & & & \\
\hline $15 \mathrm{~min}$ & $\overline{100}$ & $\overline{8}$ & 140 & 12 & - & +4 & 3.7 & - \\
\hline
\end{tabular}


TABLE IV

Dog 2A

\begin{tabular}{|c|c|c|c|c|c|c|c|c|}
\hline Time & $\begin{array}{c}\text { FAP } \\
(\mathrm{mm} \mathrm{Hg})\end{array}$ & $\begin{array}{c}\text { PAP } \\
(\mathrm{mm} \mathrm{Hg})\end{array}$ & $\begin{array}{c}\text { MFAP } \\
(\mathrm{mm} \mathrm{Hg})\end{array}$ & $\begin{array}{c}\text { MPAP } \\
(\mathrm{mm} \mathrm{Hg})\end{array}$ & $\begin{array}{c}\text { MSvc } \\
(\mathrm{mm} \mathrm{Hg})\end{array}$ & $\underset{(\mathrm{mm} \mathrm{Hg})}{\mathrm{MLAP}}$ & $\begin{array}{c}\text { Cardiac } \\
\text { output } \\
\text { (L/min) }\end{array}$ & $\begin{array}{l}\text { Blood } \\
\text { loss } / \text { trans. } \\
\text { (cc) }\end{array}$ \\
\hline & 150 & 18 & & & & & & \\
\hline \multirow{2}{*}{ min } & $\overline{100}$ & $\overrightarrow{10}$ & 120 & 13 & +2 & +3 & 3.8 & - \\
\hline & 140 & 16 & & & & & & \\
\hline \multirow[t]{2}{*}{$25 \mathrm{sec}$} & $\overrightarrow{90}$ & $\overline{8}$ & 110 & 11 & +3 & +2 & 3.8 & 100 \\
\hline & 70 & 8 & & & & & & \\
\hline $2 \min$ & $\overline{30}$ & $\overrightarrow{4}$ & 50 & 6 & 0 & 0 & - & 300 \\
\hline \multirow[t]{2}{*}{$4 \frac{1}{2} \mathrm{~min}$} & - & - & 30 & 0 & +1 & -1 & 1.9 & 550 \\
\hline & 60 & 6 & & & & & & \\
\hline \multirow[t]{2}{*}{$20 \mathrm{sec}$} & $\overline{30}$ & $\overline{2}$ & 40 & 3 & 0 & +2 & - & 100 \\
\hline & 75 & 10 & & & & & & \\
\hline \multirow[t]{2}{*}{$1 \frac{1}{2} \min$} & $\overline{40}$ & $\overline{4}$ & 50 & 6 & +2 & +5 & - & 200 \\
\hline & 80 & 15 & & & & & & \\
\hline \multirow[t]{2}{*}{$3 \mathrm{~min}$} & $\overline{40}$ & 10 & 55 & 12 & +3 & +7 & 1.8 & 400 \\
\hline & 90 & 28 & & & & & & \\
\hline \multirow[t]{2}{*}{$4 \frac{1}{2} \mathrm{~min}$} & $\overrightarrow{50}$ & $\overline{14}$ & 75 & 19 & +4 & +12 & 2.8 & 550 \\
\hline & 130 & 17 & & & & & & \\
\hline $15 \mathrm{~min}$ & $\overline{100}$ & $\overline{12}$ & 120 & 14 & +2 & +2 & 3.6 & - \\
\hline
\end{tabular}

TABLE $\mathrm{V}$

Dog 3

\begin{tabular}{|c|c|c|c|c|c|c|c|c|}
\hline Time & $\begin{array}{c}\mathrm{FAP} \\
(\mathrm{mm} \mathrm{Hg})\end{array}$ & $\begin{array}{c}\text { PAP } \\
(\mathrm{mm} \mathrm{Hg})\end{array}$ & $\begin{array}{c}\text { MFAP } \\
(\mathrm{mm} \mathrm{Hg})\end{array}$ & $\begin{array}{c}\text { MPAP } \\
(\mathrm{mm} \mathrm{Hg})\end{array}$ & $\begin{array}{c}\mathrm{MSVC} \\
(\mathrm{mm} \mathrm{Hg})\end{array}$ & $\begin{array}{c}\text { MLAP } \\
(\mathrm{mm} \mathrm{Hg})\end{array}$ & $\begin{array}{c}\text { Cardiac } \\
\text { output } \\
\text { (L/min) }\end{array}$ & $\begin{array}{c}\text { Blood } \\
\text { loss/trans } \\
\text { (cc) }\end{array}$ \\
\hline \multirow{3}{*}{$\begin{array}{l}0+60 \\
\min \end{array}$} & 160 & 16 & & & & & & \\
\hline & 110 & 10 & 150 & 13 & +2 & +2 & 3.6 & - \\
\hline & 160 & 12 & & & & & & \\
\hline \multirow[t]{2}{*}{$20 \mathrm{sec}$} & 100 & 8 & 140 & 10 & +3 & +3 & - & 100 \\
\hline & $\underline{160}$ & 10 & & & & & & \\
\hline \multirow[t]{2}{*}{$1 \mathrm{~min}$} & $\overline{95}$ & $\overline{7}$ & 140 & 9 & +3 & +1 & - & 150 \\
\hline & 80 & & & & & & & \\
\hline $3 \mathrm{~min}$ & $\overline{30}$ & - & 50 & 3 & +2 & -2 & 2.0 & 300 \\
\hline $4 \frac{1}{2} \mathrm{~min}$ & 400 & - & 30 & 0 & 0 & -2 & - & 400 \\
\hline \multirow[t]{2}{*}{$25 \mathrm{sec}$} & - & - & 40 & 3 & -2 & -2 & - & 100 \\
\hline & & 9 & & & & & & \\
\hline \multirow[t]{2}{*}{$2 \mathrm{~min}$} & - & $\overline{6}$ & 60 & 7 & +2 & 0 & 2.2 & 200 \\
\hline & $\underline{130}$ & $\underline{23}$ & & & & & & \\
\hline \multirow[t]{2}{*}{$4 \mathrm{~min}$} & $\overline{80}$ & $\overline{16}$ & 90 & 19 & +3 & +6 & - & 400 \\
\hline & 190 & 11 & & & & & & \\
\hline $15 \mathrm{~min}$ & 110 & 8 & 160 & 12 & +2 & +2 & 3.4 & - \\
\hline
\end{tabular}




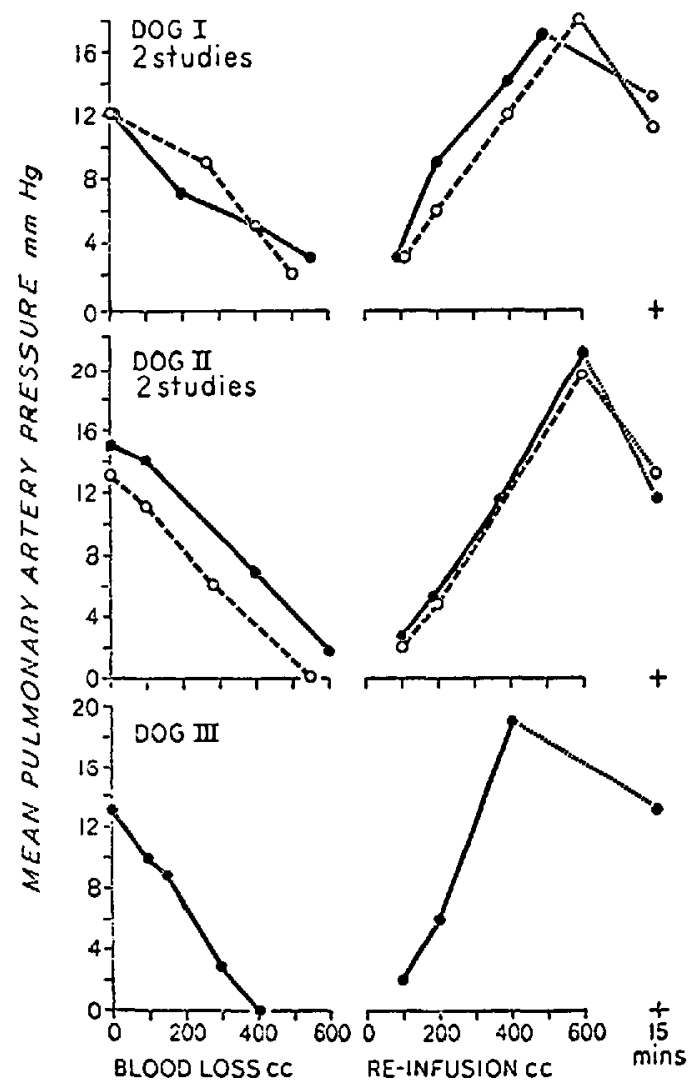

Figure 1. Relation between blood loss and mean pulmonary arterial pressure.

\section{Mean left atrial pressure (Fig. 2)}

The average baseline pressure was $+2.5 \mathrm{~mm} \mathrm{Hg}$, with a range of -2 to +3 $\mathrm{mm} \mathrm{Hg}$. There was no definite correlation with the degree of blood loss, but negative values from $-1 \mathrm{~mm} \mathrm{Hg}$ to $-2 \mathrm{~mm} \mathrm{Hg}$ were always reached at the end of the bleeding period. Retransfusion caused a marked increase in left atrial pressure, rising to an average value of $8 \mathrm{~mm} \mathrm{Hg}$-an increase of nearly 200 per cent.

\section{Mean central venous pressure (Fig. 3)}

This showed quite varied baseline values even in the same dog studied on different occasions. It had a range of $-2 \mathrm{~mm} \mathrm{Hg}$ to $+4 \mathrm{~mm} \mathrm{Hg}$. There was no consistent correlation between blood loss and mean pressure, and the variation even in the same dog studied on different occasions was marked. Retransfusion always caused some rise in pressure but there was never any marked increase above baseline values. 


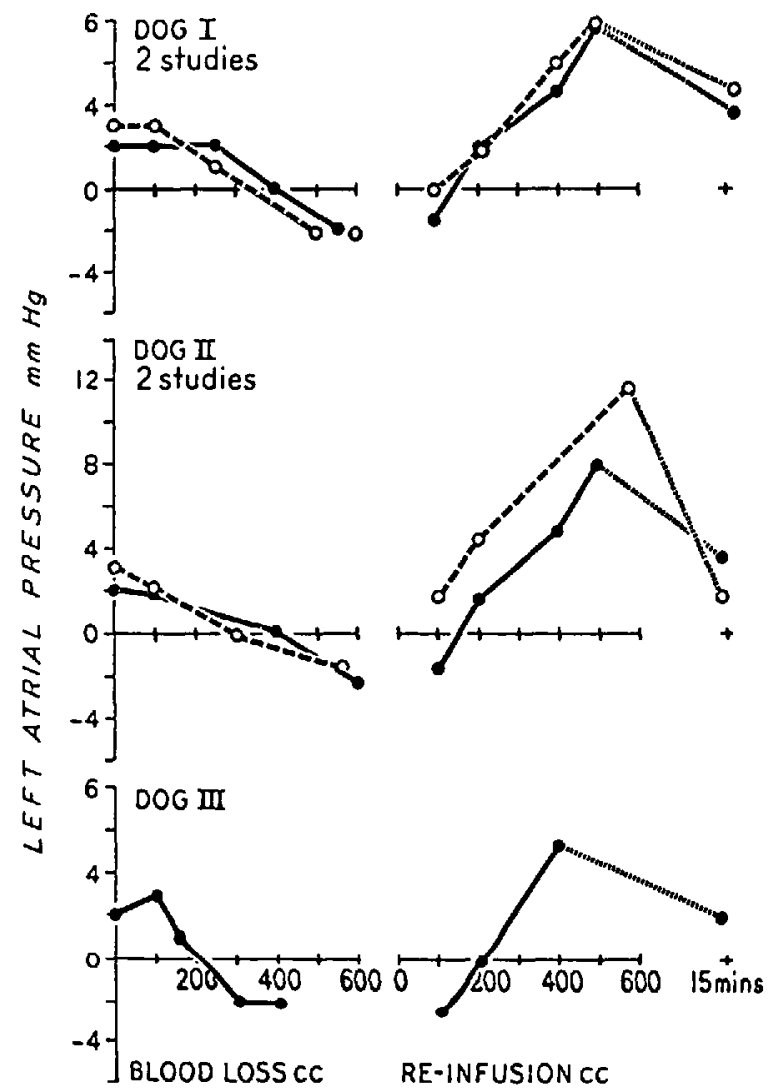

Figure 2. Relation between blood loss and left atrial pressure.

\section{Mean femoral artery pressure (Fig. 4)}

The average mean baseline value was $145 \mathrm{~mm} \mathrm{Hg}$. The correlation with blood loss was more consistent than in the case of central venous pressure but the tendency was to maintain the pressure early in the bleeding period, with a dramatic decrease later on. The return to normal pressure with retransfusion was slow but end-transfusion mean pressure averaged only $70 \mathrm{~mm} \mathrm{Hg}$-only 50 per cent of the baseline values. At 15 minutes the value had returned to normal.

\section{Cardiac output}

Baseline values were surprisingly high, averaging $4.0 \mathrm{~L} / \mathrm{min}$. There was a marked decrease with haemorrhage, of course, to values not measurable with our technique. Retransfusion did not immediately return the value to normal.

\section{Discussion}

The problems related to haemorrhagic shock and the occasional inability to rcstore the cardiovascular status to normal merely by retransfusion of cstimated blood loss have been investigated for many years. Many explanations have been 


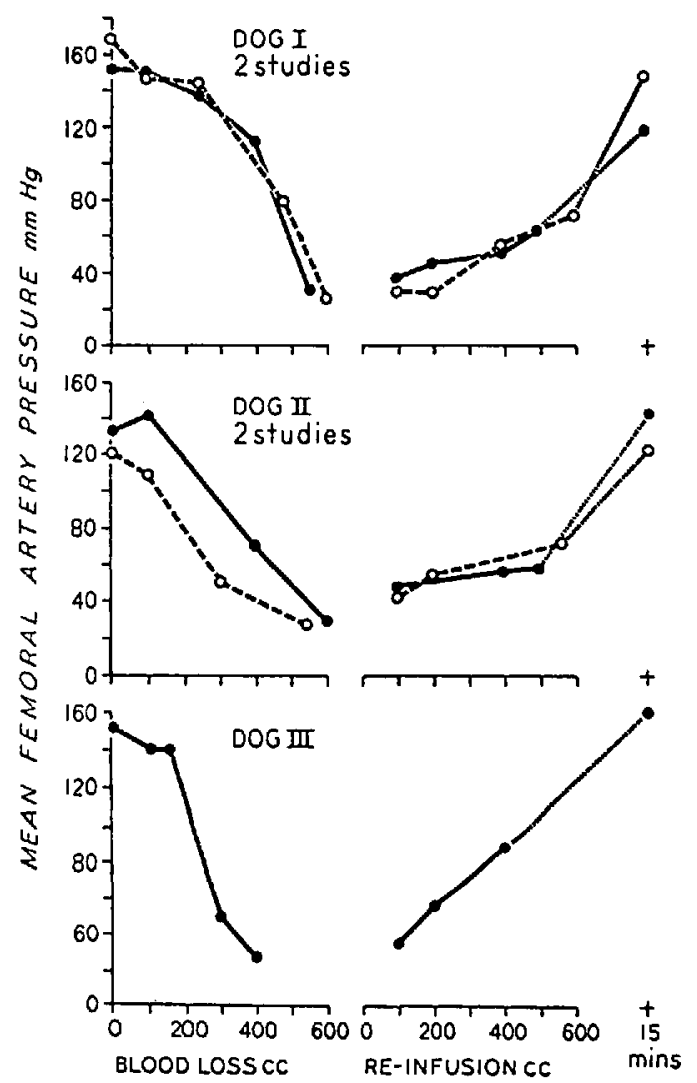

Figure 3. Relation between blood loss and mean femoral arterial pressure.

proposed, but until recently much attention has been focused on the peripheral vasculature, and the role of the myocardium has been somewhat ignored. Crowell and Guyton, ${ }^{2}$ Weidner, ${ }^{3}$ Simeone, ${ }^{4}$ Gregg, ${ }^{5}$ and others have done much work on this problem but the conclusions reached differ considerably. This is probably due to experimental methods and the criteria used to assess myocardial function.

Guyton $^{2}$ has constructed elegant experimental cardiac output/left atrial pressure curves which show the increasing depression of myocardial contractility as the duration of the hypotensive episode increases.

Weidner, ${ }^{3}$ however, assessed myocardial contractility with a Walter-Brodie strain gauge and showed that there was severe depression in the first 10-15 minutes of the hypotensive period but afterwards contractility increased to within normal limits.

Gregg $^{5}$ recorded the change in coronary flow with haemorrhage and showed that a rapid decrease is followed by a gradual increase, again after 10 to 15 minutes of hypotension. Studies of coronary flow in general, however, are inconclusive due to the summation effects of pressure and resistance, the two factors governing flow.

The degree of myocardial ischaemia has been assessed by Simeone ${ }^{4}$ and also 


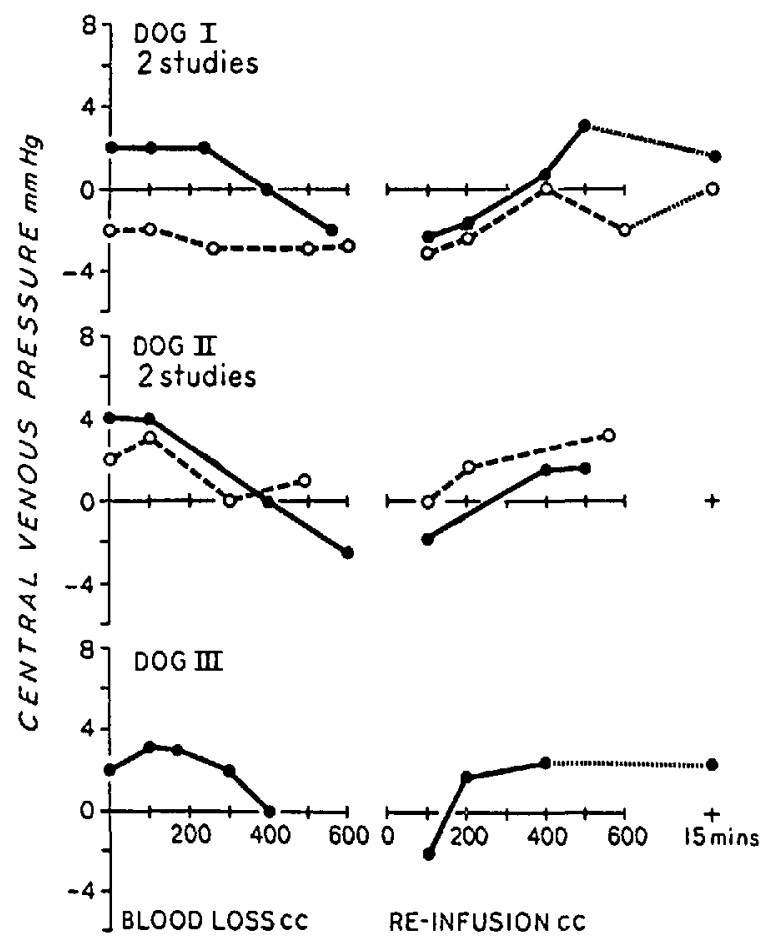

Figure 4. Relation between blood loss and mean central venous pressure.

more recently by Lundsgaard-Hansen, ${ }^{6}$ with rather inconclusive results. Simeone demonstrates myocardial ischaemia; Hansen, no ischaemia. The effect of halothane and nitrous oxide on myocardial contractility has been investigated by many workers, especially Price, ${ }^{7}$ Goldberg, ${ }^{8}$ and Smith, ${ }^{9}$ and more recently by Shinozaki et al., ${ }^{10}$ with the fairly general conclusion that halothane and nitrous oxide are both direct myocardial depressants, although of course of different potencies.

Our results appear to support the findings of Weidner, ${ }^{3}$ viz: that during the initial hypotensive episode there is a depression of myocardial contractility leading to a poor response to retransfusion. This is reflected by the rise in mean pulmonary arterial pressure, mean left atrial pressure, poor systemic arterial pressure response and low cardiac output.

The myocardium is in a state of constant flux, and one can easily visualize the position of the curves constructed by Guyton ${ }^{2}$ swinging from right to left and left to right as the various conditions affecting myocardial contractility change. In fact, perhaps these curves of myocardial activity should be three dimensional and the different results of various workers are merely tomograms, as it were, of this three-dimensional figure. The tomograms would cross the various plate-like isobars (isobars which may relate any number of conditions; for example, hypoxia, electrolyte imbalance, trauma, chemical insult to left atrial and end diastolic pressure and cardiac work) at numerous points. 
This study demonstrates again that central venous pressure can be a poor indicator of the degree of blood loss. Spencer et al. ${ }^{11}$ found that pulmonary artery pressure was a better indicator of blood volume change during overtransfusion than central venous pressure, and our results indicate that this may also be true during haemorrhage. It would also appear that mean pulmonary artery pressure and mean left atrial pressure are better indicators of "myocardial capacity" than central venous pressure.

The significance of these results in clinical practice is somewhat difficult to assess. However, we may theorize that a massive haemorrhage in a patient with an already partially compromised myocardium may lead to severe myocardial depression, even without the often quoted factors supposedly leading to this depression, such as hypothermia, hypocalcaemia, hyperkalaemia, and metabolic acidosis. As such, the myocardium will not respond to immediate retransfusion of blood and there may not be the expected rise in blood pressure. There may, in fact, be a need for some myocardial stimulation during this stage.

\section{SUMMARY}

The effects of massive haemorrhage and retransfusion on certain cardiovascular parameters in the dog are reported. The results would indicate a degree of myocardial depression after a massive haemorrhage, which leads to poor immediate response to transfusion. There seems to be a fair correlation between mean pulmonary arterial pressure and blood loss, but the response of the central venous pressure and arterial blood pressure is unpredictable.

\section{RÉSUMÉ}

Nous signalons les effets d'une hémorragie massive et d'une re-transfusion sur certains paramètres cardio-vasculaires chez le chien. Les résultats sembleraient laisser voir un certain degré de dépression myocardique après une hémorragie massive, dépression qui donne une faible réponse immédiate à la transfusion. Il semble exister une bonne corrélation entre la pression moyenne dans l'artère pulmonaire et la perte sanguine, mais la réponse sur la tension veineuse centrale et la pression artérielle est imprévisible.

\section{REFERENCES}

1. Evans, D. \& Boyes, A. W. Chronic Catheterization of Blood Vessels in the Dog. Canad. Anaesth. Soc. J. 15: 135 (1968).

2. Cadwell, J. W. \& Guyton, A. C. Further Evidence Favouring Cardiac Mechanism in Hemorrhage Shock. Am. J. Physiol. 203: 248 (1962).

3. Wemner, M. G.; Roth, L.; \& Smeone, F. A. Myocardial Response to Prolonged Acute Oligemic Hypotension. Surgery. 50: 75 (1961).

4. Simeone, F. A.; Hugn, E. A.; \& Wemner, M. G. The Effect of 1-Norepinephrine upon the Myocardial Oxygen Tension and Survival in Acute Hemorrhagic Shock. Surgery. 44: 168 (1958).

5. GhegG, D. E. Hemodynamic Factors in Shock. "Shock" International Symposium. Springer Verlag (1962).

6. Lundsgand-Hansen, P. Oxygen Supply and Anaerobic Metabolism of the Heart in Experimental and Hemorrhagic Shock. Ann. Surg. 163: 10 (1966). 
7. Price, W. L. \& Price, M. L. Has Halothane a Predominantly Circulatory Action? Anesthesiology. 27: 764 (1966).

8. Goldierg, A. H. \& Ullaick, W. C. Effect of Halothane on Isometric Contraction of Isolated Heart Muscle. Anesthesiology. 28: 838 (1966).

9. Smith, T. N. \& Consascio, A. N. The Cardiovascular Effect of Nitrous Oxide during Halothane Anesthesia. Anesthesiology. 27: 5 (1966).

10. Shinozaki, T.; Mazuzan, J. E.; \& Abajian, J. Halothane and the Heart. Brit. J. Anaesth. 40:79 (1968).

11. Spencer, F. C.; Yu, S. C.; \& Rossr, N. P. Intra-cardiac Pressure Changes with Overtransfusion in Normal Dogs. Ann. Surg. 162: 74 (1965). 